\title{
Low Energy Electron Microscopy of Indium on Si(001) Surfaces
}

\author{
H. A. McKay and R. M. Feenstra \\ Department of Physics, Carnegie Mellon University, Pittsburgh, Pennsylvania 15213
}

\section{EXPERIMENT}

Low energy electron microscopy is used to study the behavior of thin indium films on $\mathrm{Si}(001)$ surfaces from $100^{\circ} \mathrm{C}$ up to $700^{\circ} \mathrm{C}$. For temperatures below $150^{\circ} \mathrm{C}$ we see inversions in the LEEM dark-field image and LEED 1/2-order spot intensities as indium coverage increases from 0 to $2 \mathrm{ML}$. For temperatures between $150^{\circ} \mathrm{C}$ and $600^{\circ} \mathrm{C}$ we find the formation of a disordered and an ordered $(4 \times 3)$ indium phase on the surface. For temperatures above $500^{\circ} \mathrm{C}$ we observe significant rearrangement of the $\mathrm{Si}(001)$ surface due to the presence of indium and etching of the $\mathrm{Si}(001)$ surface by indium at temperatures greater than $650^{\circ} \mathrm{C}$.

\section{INTRODUCTION}

Knowledge of the behavior of group III metal atoms on clean $\mathrm{Si}(001)(2 \times 1)$ surfaces is useful in understanding how such atoms are incorporated into the material as dopants during molecular beam epitaxy (MBE), or for understanding how III-V compound semiconductor materials grow on $\mathrm{Si}(001)^{1}$. Indium is an acceptor in silicon, and it has been observed to strongly surface segregate during silicon $\mathrm{MBE}^{2}$. It also has applications for low temperature surface cleaning of silicon as a prelude to silicon $\mathrm{MBE}^{3}$.

The behavior of indium on clean $\mathrm{Si}(001)$ has previously been extensively studied over a range of temperatures using LEED and RHEED ${ }^{4,5}$. Room temperature STM has also been used to study the two main reconstructions of indium on $\mathrm{Si}(001)^{6^{-9}}$. For temperatures below $150^{\circ} \mathrm{C}$ the dominant reconstructions on the surface are a mix of $\operatorname{In}(2 \times 2)$ and $\operatorname{Si}(2 \times 1)$ until a coverage $(\theta)$ of 0.5 monolayers (ML) when the surface is fully $\operatorname{In}(2 \times 2)$. Additional less pronounced reconstructions have been reported above and below $0.5 \mathrm{ML}^{7,8}$. Above $150^{\circ} \mathrm{C}$ the reconstruction is a mix of $\operatorname{In}(4 \times 3)$ and $\operatorname{Si}(2 \times 1)$ until $\theta=0.5 \mathrm{ML}$ when the surface becomes fully $\operatorname{In}(4 \times 3)$. Adding additional indium to the surface results in the formation of three dimensional islands below $150^{\circ} \mathrm{C}$ and indium droplets above $150^{\circ} \mathrm{C}$.

Low energy electron microscopy (LEEM) is a relatively new tool in surface science ${ }^{10}$. Using LEEM it is possible to probe the surface in real space and real time. In the past LEEM has been used to study $\mathrm{Pb}^{11}, \mathrm{Ag}^{12}, \mathrm{Au}^{13}$, $\mathrm{B}^{14,15}$ and $\mathrm{O}^{16,17}$ adsorbates on $\mathrm{Si}(001)$ at various temperatures. In this work we will use LEEM to probe the dynamics of indium on $\mathrm{Si}(001)$ from room temperature up to $700^{\circ} \mathrm{C}$.
Silicon substrates were cut from two-inch wafers manufactured by Virginia Semiconductor. The wafers were doped with $\mathrm{Sb}$ to a resistivity of $0.01 \mathrm{ohms}-\mathrm{cm}$ and were nominally on-axis. LEEM measurements were performed using a commercial LEEM system based on a design by Bauer $^{10}$.

$\mathrm{Up}$ to $\approx 600^{\circ} \mathrm{C}$, the substrate temperature could be controlled by adjusting the current flowing through a hot tungsten filament located behind the sample. Above $600^{\circ} \mathrm{C}$ electron-beam heating from the same filament was used to heat the sample. A W-Re thermocouple located near the substrate on the sample holder provided a means of temperature measurement. Sample temperature calibration was performed by observing the melting point of $\approx 100 \mu \mathrm{m}$ size $\mathrm{Pb}$ islands on $\mathrm{Si}(001)$ and also by observing the $(7 \times 7)$ to $(1 \times 1)$ surface phase transition during LEED on $\mathrm{Si}(111)$.

Typical sample preparation involved rinsing the silicon piece first in acetone, then in propanol and finally in de-ionized water before introducing it into the UHV chamber through a load-lock. Samples were then outgassed for 12 hours at $500-600^{\circ} \mathrm{C}$.

Dark field LEEM images were obtained by briefly heating the substrates to $1000-1200^{\circ} \mathrm{C}$ to remove the oxide and order the surface. The sample was allowed to cool and the incident electron beam was then tilted to allow the magnified 1/2-order $\operatorname{Si}(100)(2 \times 1)$ diffraction spot to impinge upon the imaging screen.

Indium could be deposited either from a hot filament or an electron-beam heated molybdenum crucible. The indium flux from the hot filament was monitored with a quartz crystal microbalance. Indium flux from the ebeam source was monitored by collecting a fraction of the ionized flux current from the crucible. The flux monitor devices were calibrated by observing the transition from $(2 \times 1)$ to $(2 \times 2)$ of the $\mathrm{In} / \mathrm{Si}(001)$ LEED pattern for $\mathrm{T}$ $<150^{\circ} \mathrm{C}$. Indium coverages and fluxes stated in this paper will be referenced to an unreconstructed $\mathrm{Si}(100)$ surface where $1 \mathrm{ML}=6.78 \times 10^{14}$ atoms $/ \mathrm{cm}^{2}$.

The angle between the indium source directions and the sample plane in the LEEM was $\approx 16^{\circ}$. This small angle restricted the indium flux incident on the sample surface. This was not a problem for substrate temperatures where the indium desorption rate was small. For higher temperatures, however, the indium flux at the source needed to be quite large to make up for the effects of the shallow deposition angle. Large indium fluxes led to higher chamber background pressures which often interfered with LEEM operation. 
The indium flux from the e-beam source took on the order of 20 minutes to come to a new equilibrium value after changing the source parameters. Figure 1 shows a typical plot of indium flux as a function of time. The plot show discontinuous jumps in the flux when source parameters were changed to raise the deposition rate (marked with arrows on the figure). After a change, the plot shows that the flux tends to increase over time. In many of the experiments described below we increased the flux during the experiment in a step-wise manner, as in Fig. 1, in order to acheive a comprehensive view of the surface evolution.

For observations of the behavior of indium on $\mathrm{Si}(001)$ it was convenient to have the surface decorated with micron-scale terraces. Since the actual miscut angle of the silicon wafers used in this study did not allow for such an equilibrium arrangement, intensive substrate cleaning was not undertaken. This allowed some impurities to remain on the surface. By observing the dark field image of the surface and suitable adjustment of the substrate temperature it was possible to form large $(2 \times 1)$ or $(1 \times 2)$ terraces in the vicinity of a surface impurity.

\section{RESULTS AND DISCUSSION}

The behavior of indium on $\mathrm{Si}(001)$ was characterized by observing the $\mathrm{Si}(100)$ surface using dark field LEEM. In this imaging mode, one of the $\operatorname{Si}(100)(2 \times 1)$ halforder diffraction spots is used to form the LEEM image. Terraces on the $\mathrm{Si}(100)$ surface which have a $(2 \times 1)$ reconstruction will appear bright in the LEEM image while $(1 \times 2)$-reconstructed terraces will appear dark. The geometry of the $\mathrm{Si}(001)$ surface is such that terraces which are separated by an odd number of atomic steps will have reconstructions rotated by $90^{\circ}$. An image of the surface shows an alternating series of light and dark terraces.

\section{A. Temperature $<150^{\circ} \mathrm{C}$}

At a substrate temperature below about $150^{\circ} \mathrm{C}$, it has been shown that as indium is deposited on clean $\mathrm{Si}(001)$ the LEED pattern, which was initially $(2 \times 1)$, becomes streaky. As the indium coverage increases, the streaks coalesce into sharper diffraction spots and the LEED pattern becomes $(2 \times 2)$ at $\theta=0.5 \mathrm{ML}^{4}$.

Figure 2 shows a sequence of dark field LEEM images of the surface as indium is deposited at $\approx 0.1 \mathrm{ML} /$ minute from the hot filament indium source. The LEEM image starts out with sharp black and white contrast between $(2 \times 1)$ and $(1 \times 2)$ terraces (Fig. $2(\mathrm{a}))$. As indium is deposited the image contrast decreases (Fig. 2(b)). It reaches a minimum near $0.3 \mathrm{ML}$ (Fig. 2(c)). Contrast increases again until it reaches a maximum near $0.6 \mathrm{ML}$ (Fig. 2(d)). At this coverage the original image contrast is inverted with $(2 \times 1)$ terraces appearing white and
$(1 \times 2)$ terraces appearing black. With increasing coverage the contrast fades again, passing through a minimum at 1.6 ML (Fig. 2(g)) and reverting to the original polarity, but with much less image intensity, as $\theta$ reaches 2 ML (Fig. 2(h)). Starting from $0 \mathrm{ML}$, the overall LEEM image intensity decreases with increasing indium coverage. Past $3 \mathrm{ML}$ larger three dimensional islands begin to grow on the surface. It should be noted that there is an oval-shaped dark spot visible near the middle of many dark field images presented in this work. This feature is associated with the micro-channel plate imaging screen and not the $\mathrm{Si}(001)$ surface. The defect is most notable when the image intensity is low (i.e. Figs. 2(c), (g), and (h)).

Figure 3 shows a sequence of LEED patterns taken using the same deposition rate as in Figure 2. The 1/2order spot used for LEEM imaging is marked (Fig. 3(b)). The incident electron energy used for this LEED pattern is 3.6 volts and the area illuminated on the surface by the electron beam is a circle $\approx 10 \mu \mathrm{m}$ in diameter. A line cut passing through the $(0,1 / 2)$ and the $(1 / 2,0)$ diffraction spots is shown to the side of each image, showing the relative intensities of the two $1 / 2$-order spots. The $(1 / 2,0)$ spot has roughly half as much intensity as the $(0,1 / 2)$ spot indicating that the illuminated area is not equally divided between $(2 \times 1)$ and $(1 \times 2)$ terraces. As the indium coverage increases the intensities of the $1 / 2$-order spots in the pattern match up with what is expected based on the LEEM images (i.e. the $(2 \times 1)$ spots are least intense at the same time the $(1 \times 2)$ spots are most intense). As $\theta$ rises to $0.5 \mathrm{ML}$ streaks and additional diffraction spots develop in the LEED pattern. Past 0.5 ML, the streaks fade as do the additional spots. Additional minority reconstructions have been reported from STM observations of $\mathrm{In} / \mathrm{Si}(001)$ at room temperature ${ }^{7,8}$. At an incident energy of 60 volts the intensities of the $(0,1 / 2)$ and $(1 / 2,0)$ merely decrease with increasing indium coverage, i.e. they do not invert.

The $1 / 2$-order spot intensities vary with indium coverage at 3.6 volts. Consequently we see variations in the dark field image. The mechanism(s) behind this behavior are not obvious. The inversions are probably linked to the details of the I-V curves for the $1 / 2$-order spots in the $(2 \times 2)$ In phase and the $(2 \times 1)$ clean surface reconstruction, and how those curves evolve as a function of In coverage. LEED I-V results for these two structures ${ }^{18,19}$ do not extend down to the low energies used here for LEEM, and in any event the features in an I-V curve can be difficult to relate to specific structural models of the surface $^{20}$.

At no time during indium depositions at this temperature $\left(\approx 100^{\circ} \mathrm{C}\right)$ do we see any islands form on the terraces. This is in contrast to STM observations of indium deposited on silicon near room temperature ${ }^{9}$. Though $(2 \times 2)$ domains may be forming in our experiments, they are apparently too small to resolve with this instrument. 


\section{B. $150^{\circ} \mathrm{C}<$ Temperature $<600^{\circ} \mathrm{C}$}

Above $150^{\circ} \mathrm{C}$ and for $\theta>0.1 \mathrm{ML}$, LEED of indium on $\mathrm{Si}(001)$ shows a $(4 \times 3)$ reconstruction ${ }^{4}$. Figure 4 shows an example of the LEED pattern evolving from $(2 \times 1)$ (Fig. $4(\mathrm{a}))$ to $(4 \times 3)$ (Fig. $4(\mathrm{~d}))$ as indium is deposited on a substrate held at $500^{\circ} \mathrm{C}$. We note that unlike $\mathrm{T}<150^{\circ} \mathrm{C}$, the desorption rate of indium from $\mathrm{Si}(001)$ at higher temperatures can be substantial and since we do not know the magnitude of the desorption rate at these temperatures we cannot give values for the absolute surface coverage. In the figure captions we state the incident indium flux and the time from opening the source shutter. Figure 5 shows a sequence of images acquired at $\mathrm{T}=330^{\circ} \mathrm{C}$ at indium fluxes ranging from 0 to $7.5 \mathrm{ML} /$ minute. As soon as the $(4 \times 3)$ reconstruction forms, the image intensity decreases due to the outgoing electron beam being divided among many new diffraction spots (Fig. 5(b)). Contrast between $(2 \times 1)$ and $(1 \times 2)$ terraces decreases. However, no islands or other features can be resolved on the terraces at this magnification. As more indium is deposited small droplets appear on the surface as seen in Fig. 5(c). If the indium flux is terminated the droplets appear to be stable at this temperature. A subsequent increase in the substrate temperature to $500^{\circ} \mathrm{C}$ causes the droplets to evaporate or merge into larger droplets seen in Fig. 5 (e) (note the similarity of this image to Fig. 9 of Ref. ${ }^{4}$ ), which then begin to shrink in the absence of an indium flux. Increasing the temperature again to $600^{\circ} \mathrm{C}$ causes the indium to rapidly desorb from the surface. The resulting surface, seen in Fig. 5(f), appears quite different from the starting surface. The indium appears to have altered the morphology of the underlying silicon.

At $330^{\circ} \mathrm{C}$ the desorption rate of indium from the surface is not large. At $500^{\circ} \mathrm{C}$ the desorption rate starts to become significant. In order to see a $(4 \times 3)$ LEED pattern at this temperature a larger flux than the one used at $330^{\circ} \mathrm{C}$ is needed. Except for the necessity of a higher indium flux, the appearance and behavior of the LEED patterns at $330^{\circ} \mathrm{C}$ and $500^{\circ} \mathrm{C}$ are identical. The same cannot be said for the dark field LEEM image. Figure 6 shows an example of a sequence of images taken with the substrate held near $500^{\circ} \mathrm{C}$. The indium flux was increased several times during the sequence. The film starts off with strong contrast between black and white terraces (Fig. 6(a)), but at a flux of $0.6 \mathrm{ML} /$ minute the contrast decreases (Fig. 6(b)). At a flux of $1.4 \mathrm{ML} /$ minute a new phase appears to nucleate on the surface. In the LEEM image it appears as a gray haze that grows over the surface starting from impurity mounds. It obscures but does not quite conceal the underlying terrace structure (Fig. 6(c)-(d)). A few indium droplets appear near the center of the image (Fig. 6(d)). As the flux increases past $7.8 \mathrm{ML} /$ minute a new phase condenses from parts of the gray haze. This new phase has higher bright/dark contrast (Fig. 6(e)). Fluctuations in the indium flux rate cause one phase to grow at the expense of the other. If the indium flux is increased, more gray haze appears on top of the highercontrast phase. If the indium flux is brought to zero, the hazy gray phase disappears and the higher-contrast phase dominates (Fig. 6(g) and (h)). With the flux set to zero, the substrate temperature was raised to $550^{\circ} \mathrm{C}$, causing the high-contrast phase to disappear and be replaced by an almost contrastless image. Observations of the LEED pattern show that every diffraction spot but the $(0,0)$ spot have disappeared. The surface has become disordered. Contrast returns when the disordered indium has mostly left the surface. Attempts to repeat this experiment using nominally identical substrate temperatures and indium fluxes have met with mixed results. Sometimes the high-contrast phase fails to condense out of the hazy gray phase, though existing indium droplets continue to grow. When the higher-contrast phase does appear, one is reminded of the sudden growth of crystals in a supersaturated solution. Observations of the LEED pattern during these experiments do not show much variation. The pattern is still $(4 \times 3)$. On surfaces which definitely have the high-contrast phase present, lower order $(4 \times 3)$ spots are more intense.

The above behavior appears to be complicated. There are several points to discuss. The LEED pattern shows a uniform $(4 \times 3)$ reconstruction while there appear to be variations in the dark field LEEM image. Up to 0.5 ML there is a mix of $\operatorname{Si}(001)(2 \times 1)$ and $\operatorname{In}(4 \times 3)$. The LEEM image is formed using a $1 / 2$-order spot from the electron diffraction pattern and when there is indium on the surface this spot has intensity contributions from $\operatorname{In}(4 \times 3)$ and $\operatorname{Si}(100)(2 \times 1)$ diffraction patterns. Regions of the surface which are $(4 \times 3)$ will appear bright and regions which are $(3 \times 4)$ will be dark. It may be that $(4 \times 3)$ and $(3 \times 4)$ regions do not match up exactly with terraces which were initially $(2 \times 1)$ and $(1 \times 2)$. Li et al. ${ }^{6}$ has demonstrated that terrace which are single domain $(2 \times 1)$ form predominantly single domain $\operatorname{In}(4 \times 3)$ structure, although some disruption of the underlying silicon does occur as also observed by by Baski et al. ${ }^{7}$. $\operatorname{In}(4 \times 3)$ and $(3 \times 4)$ structures end up on alternating terraces ${ }^{6,7}$. In our case, since the terraces are still resolvable the surface is probably partly $(2 \times 1)$ and partly $(4 \times 3)$ with the latter consisting of both possible domain orientations, i.e. $(3 \times 4)$ and $(4 \times 3)$. This would account for the gray haze if the domains were randomly oriented and too small to resolve. A similar effect is seen on parts of clean $\mathrm{Si}(001)$ surfaces which have a very high step density such that individual black and white terraces cannot be resolved. If the $(4 \times 3)$ regions start to acquire some long range orientational order then that would explain the high-contrast phase nucleating from the gray haze. As to the additional gray haze appearing on top of the high-contrast phase, there are reports in the literature of disordered indium nucleating on top of an ordered $(4 \times 3)$ phase $^{21}$. A schematic of this process is shown in Fig. 7 .

We can summarize the above discussion as follows. The surface starts out as clean $\mathrm{Si}(001)$ and there is sharp contrast between $(2 \times 1)$ and $(1 \times 2)$ terraces, as shown in 
Fig. 7(a). Indium deposited on the terraces forms small islands of $(4 \times 3)$ and $(3 \times 4)$, as in Fig. $7(\mathrm{~b})$. As the island concentration increases a resulting gray haze forms on the surface. At a sufficient concentration one of the island types starts to dominate the image. This highcontrast phase nucleates on the surface, as in Fig. 7(c). Increasing the indium flux puts disordered indium on top of the high-contrast $(4 \times 3)$ phase hence we again see gray haze in the image (Fig. 7(d)). If the flux is terminated the disordered indium desorbs first leaving behind the ordered $(4 \times 3)$ phase which desorbs slowly in comparison to the disordered indium.

\section{Temperature $>600^{\circ} \mathrm{C}$}

For these temperatures, the desorption rate of indium from the $\mathrm{Si}(001)$ surface is large. A higher indium flux is needed to begin to see the $(4 \times 3)$ pattern than at $\mathrm{T}=500^{\circ} \mathrm{C}$. If the flux is interrupted, the $(4 \times 3)$ pattern quickly shifts back to $(2 \times 1)$. For very large fluxes, the $(4 \times 3)$ pattern becomes a fuzzy $(1 \times 1)$. When this happens the $1 / 2$-order diffraction spots disappear and the dark-field image is lost. Contrary to other results in the literature for indium on $\mathrm{Si}(001)^{4,6}$, diffraction spots indicating (310) facet formation have not appeared in the LEED pattern (neither have we seen associated features in the LEEM image).

Dark-field LEEM and LEED have been performed near 600,650 and $700^{\circ} \mathrm{C}$. The required indium fluxes at these temperatures leads to increased background chamber pressures in the range of $10^{-9}$ to $10^{-8}$ torr. Attempts to deposit indium on surfaces hotter than $700^{\circ} \mathrm{C}$ were not successful due to electrical arcs between the sample and the grounded magnetic objective.

Figure 8 shows a sequence of images taken at $600^{\circ} \mathrm{C}$ with a varying indium flux. When the flux is increased from 0 to $0.2 \mathrm{ML} /$ minute, the LEEM image gets dimmer (i.e. has less contrast). Step edges shift slightly and rough step edges become smooth as seen in Figs. 8(a)(c). Increasing the indium flux to $0.6 \mathrm{ML} /$ minute causes islands to form in the middle of the larger bright terraces as in Fig. 8(e) and (f). From the images it should be noted that islands do not form near step edges or on terraces which are narrow. Island formation is rapid and once there is a sufficient density of islands, formation ceases. The surface has reached an equilibrium and the islands are static.

Figure 9 shows a sequence of images acquired at $650^{\circ} \mathrm{C}$. The sequence evolves in a similar fashion to the images seen at $600^{\circ} \mathrm{C}$ with the exception that the required indium fluxes are much larger, so that only near 11 $\mathrm{ML} /$ minute do islands form on the larger terraces (Fig. $9(\mathrm{c})$ ). Unlike the previous temperature, the islands are not static. Past a certain point, the randomly oriented islands which first appeared on the surface begin to fade (Fig. 9(d)-(f)). At the same time new elongated islands begin to form on the surface (Fig. $9(\mathrm{~g})$ and $(\mathrm{h})$ ), oriented along one of the $\langle 110\rangle$ directions. Let us call this specific direction [110]. The new islands continue to grow until they reach a step edge at which point new islands nucleate along the [110] direction (i.e. perpendicular to the orientation of the original islands). At a constant flux, the elongated lines alternate between [110] and [110] directions. Increasing the indium flux increases the cycling speed. Figure 10 (a)-(f) shows a complete cycle of nucleation and growth along [110] followed by the same process along [110] on a small terrace on a different part of the surface.

Figure 11 shows a sequence of images taken near $700^{\circ} \mathrm{C}$. The flux values for this sequence are not known but they are without a doubt larger than those for the sequence shown in Figs. 9 and 10, which were taken at $650^{\circ} \mathrm{C}$. Figs. $11(\mathrm{a})-(\mathrm{d})$ were acquired using an approximately constant indium flux, $F 1$, while in Figs. 11(e) and (f) the flux has been raised, such that $F 2>F 1$. As in Figs. 8 and 9, at a certain indium flux, round islands nucleate in the middle of larger terraces. Unlike the previous temperatures they tend to be solitary islands and they are not static (Fig. 11 (a)-(d)). Over time the island which forms in the middle of a large terrace grows to engulf the terrace, at which point another island of opposite polarity will nucleate in the middle of the terrace and proceed to grow. At the same time islands are nucleating on the larger terraces, step edges all over the image are receding. The process appears very similar to silicon sublimation at much higher temperatures (900 to $\left.1100^{\circ} \mathrm{C}\right)^{22}$. If the indium flux is increased again, elongated features similar to those seen at $650^{\circ} \mathrm{C}$ appear on the terraces and begin to grow (Fig. 11 (e)-(f)).

The features and behavior seen on the surface at temperatures higher than $600^{\circ} \mathrm{C}$ are consistent with two possible cases which both include indium etching of $\mathrm{Si}(001)$.

Case I: Under mid-range indium fluxes, indium is forming ordered $(4 \times 3)$ domains on the surface. At higher fluxes and temperatures above $650^{\circ} \mathrm{C}$, indium etches the $\mathrm{Si}(001)$ surface.

Case II: Under mid-range to large indium fluxes and all temperatures above $600^{\circ} \mathrm{C}$, no large ordered $\operatorname{In}(4 \times$ $3)$ domains form. The sole process which is occuring is indium etching of the $\mathrm{Si}(001)$.

At low indium flux rates we see rough step edges become smoother. Under case I, this could be caused by preferential adsorption at kink sites on the step edges by mobile indium atoms on the surface. At step edges, mobile indium atoms on the surface can have an enhanced probability of both adsorption (i.e. at kinks) and desorption (i.e. at smooth steps), because of the change in coordination number they acquire there. The film ceases to grow from the step edge as the density of kink sites decreases and the indium adsorption rate is balanced by the indium desorption rate. Under case II, the behavior of the step edges could be caused by preferential etching of kink sites on the step edges by indium. The etching rate is probably governed by the concentration of indium 
on the surface and the fact that indium preferentially desorbs from step edges. Steps on the surface are often bunched together. When the etching starts it is rapid on steps adjacent to large terraces. We see the lower step edges recede into the step bunch and the etching rate slows down as the local step density increases (which causes the local indium desorption rate to increase).

As the indium flux increases, the indium concentration on the terraces also increases with the local concentration being highest near the middle of the terrace far away from step edges. Under case I, indium forms single domain elongated islands near the middles of large terraces. Depending on the orientation of the underlying terrace, the long axes of these islands are oriented along a [110] or [110] direction. The islands cease to grow when adsorption is balanced by desorption. Under case II, with sufficient indium on the surface, vacancy islands nucleate and grow due to step etching. The etching process slows down when the local step density on the terrace has reduced the indium concentration sufficiently.

The above seem to be reasonable explanations for the processes seen at $600^{\circ} \mathrm{C}$. However, at $650^{\circ} \mathrm{C}$ the initial islands formed on the terraces are not static. Islands nucleate but then they decay and new elongated vacancy islands grow along a [110] direction rotated $90^{\circ}$ from the previous long-axis orientation. This may be happening because the source flux is rising slowly, so the surface indium concentration is not stable. The surface gets forced into a continuous vacancy island growth mode. The behavior we see in the darkfield LEEM image is then consistent with layer-by-layer etching of the $\mathrm{Si}(001)$ surface by indium.

We also note some interesting behavior seen in the LEEM sequence of Fig. 9. In Fig. 9(d), the initially nucleated islands are elongated along the [110] direction. As the indium flux increases, these islands decay and new elongated islands form (Fig. 9(g)). These new islands have their long axes oriented along the perpendicular [110] direction. We thus observe a reversal in the orientation of the islands, with both islands displaying the same type of contrast in the LEEM images (this behavior is quite distinct from the layer-by-layer etching etching seen in later stages, in which the contrast reverses between subsequent sets of vacancy islands, e.g. Fig. 10). To interpret this initial reversal, under case I, the initial elongated indium adatom islands decay and then vacancy islands form and layer-by-layer etching proceeds. Under case II, the initial elongated vacancy islands decay and are replaced by vacancy islands whose long axis is rotated $90^{\circ}$. It is conceivable that the surface energy would vary with indium concentration and thus allow a rotation of the preferred long axis of vacancy islands, but this would entail a rather complicated mechanism. For this reason, we feel that case I provides the most likely explanation for our LEEM observations.

\section{SUMMARY}

We have observed the behavior of indium on $\operatorname{Si}(001)$ surfaces at various temperatures using dark-field LEEM. For substrate temperatures below $150^{\circ} \mathrm{C}$ we see an inversion of the dark-field LEEM image polarity at an estimated indium coverage of 0.6 ML. For substrate temperatures between $150^{\circ} \mathrm{C}$ and $600^{\circ} \mathrm{C}$ we see the formation of a disordered and an ordered $(4 \times 3)$ phase on the surface which is dependent on the sample temperature and the incident indium flux. For substrate temperatures above $600^{\circ} \mathrm{C}$ we observe preferential etching of the $\mathrm{Si}(001)$ surface by indium in the middle of micron-size terraces.

\section{ACKNOWLEDGMENTS}

We would like to aknowledge useful discussions with J.B. Hannon and R.M. Tromp concerning LEEM techniques. This work was supported by the U.S. National Science Foundation, grant DMR-9985898.

${ }^{1}$ P.C. Sharma, K.W. Alt, D.Y. Yeh and K.L. Wang, Appl. Phys. Lett. 75, 1273 (1999).

${ }^{2}$ J. Knall, J.-E. Sundgren, J.E. Greene, A. Rockett and S.A. Barnett, Appl. Phys. Lett. 45, 689 (1984).

${ }^{3}$ H.T. Yang and W.S. Berry, J. Vac. Sci. Technol. B 2, 206 (1984).

4 J. Knall, J.-E. Sundgren, G.V. Hansson, and J.E. Green, Surface Sci. 166, 512 (1986).

${ }^{5}$ H.W. Yeom, T. Abukawa, M. Nakamura, S. Suzuki, S. Sato, K. Sakamoto, T. Sakamoto, and S. Kono, Surface Sci. 341, 328 (1995).

${ }^{6}$ L. Li, Y. Wei, and I.S.T. Tsong, Surface Sci. 304, 1 (1994).

${ }^{7}$ A.A. Baski, J. Nogami, and C.F. Quate, Phys. Rev. B 43, 9316 (1991).

${ }^{8}$ M.M.R. Evans, J.C. Glueckstein, and J. Nogami, Surface Sci. 406, 246 (1998).

9 A.A. Baski, J. Nogami, and C.F. Quate, J. Vac. Sci Technol. A 9, 1946 (1991).

${ }^{10}$ E. Bauer, Rep. Prog. Phys. 57, 895 (1994).

${ }^{11}$ L. Li, C. Koziol, K. Wurm, Y. Hong, E. Bauer and I.S.T. Tsong, Phys. Rev. B 50, 10834 (1994).

12 T. Michely, M.C. Reuter, M. Copel and R.M. Tromp, Phys. Rev. Lett. 73, 2095 (1994).

${ }^{13}$ F.-J. Meyer zu Heringdorf, R. Hild, P. Zahl, Th. Schmidt, B. Ressel, S. Heun, E. Bauer, M. Horn-von Hoegen, Surface Sci. 480, 103 (2001).

${ }^{14}$ D.E. Jones, J.P. Pelz, Y. Hong, E. Bauer, and I.S.T. Tsong, Phys. Rev. Lett. 77, 330 (1996).

15 J.B. Hannon, N.C. Bartelt, B.S. Swartsentruber, J.C. Hamilton, and G.L. Kellogg, Phys. Rev. Lett. 79, 4226 (1997). 
${ }^{16}$ K. Wurm, R. Kliese, Y. Hong, B. Rottger, Y. Wei, H. Neddermeyer, and I.S.T. Tsong, Phys. Rev. B. 50, 1567 (1994).

17 J.B. Hannon, M.C. Bartelt, N.C. Bartelt, and G.L. Kellogg, Phys. Rev. Lett. 81, 4676 (1998).

18 B.W. Holland, C.B. Duke, and A. Paton, Surf. Sci. 140, L259 (1984), and references therein.

${ }^{19}$ H. Sakama, K. Murakami, K. Nishikata, and A. Kawazu, Phys. Rev. B 53, 1080 (1996).

${ }^{20}$ F. Jona, J.A. Strozier Jr, and W.S. Yang, Rep. Prog. Phys. 45, 527 (1982).

${ }^{21}$ K.-S. Kim, Y. Takakuwa, T. Abukawa, and S. Kono, Surface Sci. 410, 99 (1998).

${ }^{22}$ C.M. Roland, M.G. Wensell, Y. Hong, and I.S.T. Tsong, Phys. Rev. Lett. 78, 2608 (1997).

FIG. 1. A sample plot of indium flux from the e-beam source. Discontinuities occur in the plot after source parameters were changed to increase the indium flux (marked by arrows). The indium flux is only approximately constant during the deposition. The estimated uncertainty in the flux values is $0.1 \mathrm{ML} /$ minute.

FIG. 2. A sequence of dark-field LEEM images taken at $\mathrm{T}<150^{\circ} \mathrm{C}$ using an indium deposition rate of $0.1 \mathrm{ML} /$ minute. The field of view is $10 \mu \mathrm{m}$ and the imaging voltage is $3.6 \mathrm{~V}$. Frames (a)-(h) were taken at 0s, 94s, 172s, 360s, 630s, 652s, $936 \mathrm{~s}$, and 1298s after opening the source shutter. An oval feature is visible in $(\mathrm{c}),(\mathrm{g})$ and $(\mathrm{h})$. This feature is present in all images shown in this work and is due to a defect in the imaging screen; it is most prominent when the image intensity is low.

FIG. 3. A sequence of LEED patterns taken during indium deposition at $\mathrm{T}<150^{\circ} \mathrm{C}$. Plots on the right are line cuts which pass through the $(0,1 / 2)$ and $(1 / 2,0)$ diffraction spots. A sample line is shown in (a). The diffraction spot used for dark-field imaging is marked with an arrow in (b). The incident electron energy is $3.6 \mathrm{~V}$ and the deposition rate is 0.1 $\mathrm{ML} /$ minute. Frames (a)-(h) were taken at $0 \mathrm{~s}, 96 \mathrm{~s}, 196 \mathrm{~s}, 296 \mathrm{~s}$, $396 \mathrm{~s}, 496 \mathrm{~s}, 596 \mathrm{~s}, 786 \mathrm{~s}$ after opening the source shutter. Note: the vertical intensity scale on $(\mathrm{a})$ is $\approx 3$ times larger than the constant scale in figures (b)-(h).

FIG. 4. A series of images showing the evolution of the diffraction pattern from $(2 \times 1)$ to $(4 \times 3)$ as indium is deposited on $\mathrm{Si}(001)$ at $500^{\circ} \mathrm{C}$. The incident electron energy is $4 \mathrm{eV}$. At this temperature we no longer know the absolute value of the surface coverage. Instead we state the incident indium flux and time from opening the source shutter.(a) $0 \mathrm{~s}, 0 \mathrm{ML} /$ minute, (b) $236 \mathrm{~s}, 0.5 \mathrm{ML} /$ minute, (c) $266 \mathrm{~s}$, $0.6 \mathrm{ML} /$ minute, (d) $304 \mathrm{~s}, 0.8 \mathrm{ML} /$ minute.
FIG. 5. A sequence of dark-field LEEM images taken during indium deposition on $\mathrm{Si}(001)$. The field of view is $25 \mu \mathrm{m}$. (a) $0 \mathrm{~s}, 0 \mathrm{ML} /$ minute, $330^{\circ} \mathrm{C}$, (b) $192 \mathrm{~s}, 0.2$ $\mathrm{ML} /$ minute, $330^{\circ} \mathrm{C}$ (c) $834 \mathrm{~s}, 7.5 \mathrm{ML} /$ minute, $330^{\circ} \mathrm{C}$, (d) $1384 \mathrm{~s}, 0 \mathrm{ML} /$ minute, $330^{\circ} \mathrm{C}$, (e) $1414 \mathrm{~s}, 0 \mathrm{ML} /$ minute, $500^{\circ} \mathrm{C}$, (f) $1504 \mathrm{~s}, 0 \mathrm{ML} /$ minute, $550^{\circ} \mathrm{C}$.

FIG. 6. A sequence of $10 \mu \mathrm{m}$ field of view dark-field images taken at $500^{\circ} \mathrm{C}$ showing the formation of $\operatorname{In}(4 \times 3)$ phases. (a) $0 \mathrm{~s}, 0 \mathrm{ML} /$ minute, (b) $372 \mathrm{~s}, 0.6 \mathrm{ML} /$ minute, (c) $470 \mathrm{~s}, 1.4 \mathrm{ML} /$ minute, (d) $610 \mathrm{~s}, 7.7 \mathrm{ML} /$ minute, (e) $624 \mathrm{~s}, 7.8 \mathrm{ML} /$ minute, (f) $794 \mathrm{~s}, 12.5 \mathrm{ML} /$ minute, (g) $868 \mathrm{~s}$, $0 \mathrm{ML} /$ minute, (h) $888 \mathrm{~s}, 0 \mathrm{ML} /$ minute. The indium flux is increase from (a) to (f) and a disordered, then ordered plus disordered $\operatorname{In}(4 \times 3)$ phase grows on the surface. The flux is interrupted in $(\mathrm{g})$ and the disordered phase desorbs quickly.

FIG. 7. A schematic diagram showing the evolution of the surface seen in Fig. 6. (a) The surface begins as clean $\operatorname{Si}(001)(2 \times 1)(b)$ Small In $(4 \times 3)$ and $(3 \times 4)$ domains nucleate on top of the $\mathrm{Si}(2 \times 1)(\mathrm{c})$ As indium surface coverage increases one of either the $(4 \times 3)$ or $(3 \times 4)$ orientational domains begins to dominate parts of the surface (d) A disordered indium layer nucleates on top of the $(4 \times 3)$ domains producing gray haze in the LEEM image.

FIG. 8. A sequence of $10 \mu \mathrm{m}$ field of view dark-field images taken at $600^{\circ} \mathrm{C}$ showing the formation of static islands on the surface as the flux increases. (a) $0 \mathrm{~s}, 0 \mathrm{ML} /$ minute, (b) $1316 \mathrm{~s}, 0.2 \mathrm{ML} /$ minute, (c) $1800 \mathrm{~s}, 0.4 \mathrm{ML} /$ minute, (d) $2030 \mathrm{~s}, 0.6 \mathrm{ML} /$ minute, (e) $2310 \mathrm{~s}, 1.0 \mathrm{ML} /$ minute, (f) $2625 \mathrm{~s}$, $1.6 \mathrm{ML} /$ minute.

FIG. 9. A sequence of $10 \mu \mathrm{m}$ field of view dark-field images taken at $650^{\circ} \mathrm{C}$ showing the beginning of continuous etching of the $\operatorname{Si}(001)$ surface by indium as the indium flux is raised. (a) $0 \mathrm{~s}, 0 \mathrm{ML} /$ minute, (b) $236 \mathrm{~s}, 3.8 \mathrm{ML} /$ minute, (c) $520 \mathrm{~s}, 11.1 \mathrm{ML} /$ minute, (d) $540 \mathrm{~s}, 11.4 \mathrm{ML} /$ minute, (e) $680 \mathrm{~s}$, $11.5 \mathrm{ML} /$ minute, (f) $756 \mathrm{~s}, 13.1 \mathrm{ML} /$ minute, (g) $788 \mathrm{~s}, 13.8$ $\mathrm{ML} /$ minute, (h) $988 \mathrm{~s}, 12.4 \mathrm{ML} /$ minute.

FIG. 10. A sequence of images showing the etching cycle on a terrace at $650^{\circ} \mathrm{C}$. The images are about $4.5 \mu \mathrm{m}$ on a side.

FIG. 11. A sequence of $5 \mu \mathrm{m}$ field of view dark-field images taken at $700^{\circ} \mathrm{C}$ showing the etching of the $\mathrm{Si}(001)$ surface by indium. Flux values are known only qualitatively for this sequence. (a) 315s, F1, (b) 395s, F1, (c) 445s, F1, (d) 546s, F1, (e) 701s, F2, (f) 801s, F2, ( with F2>F1 ). 

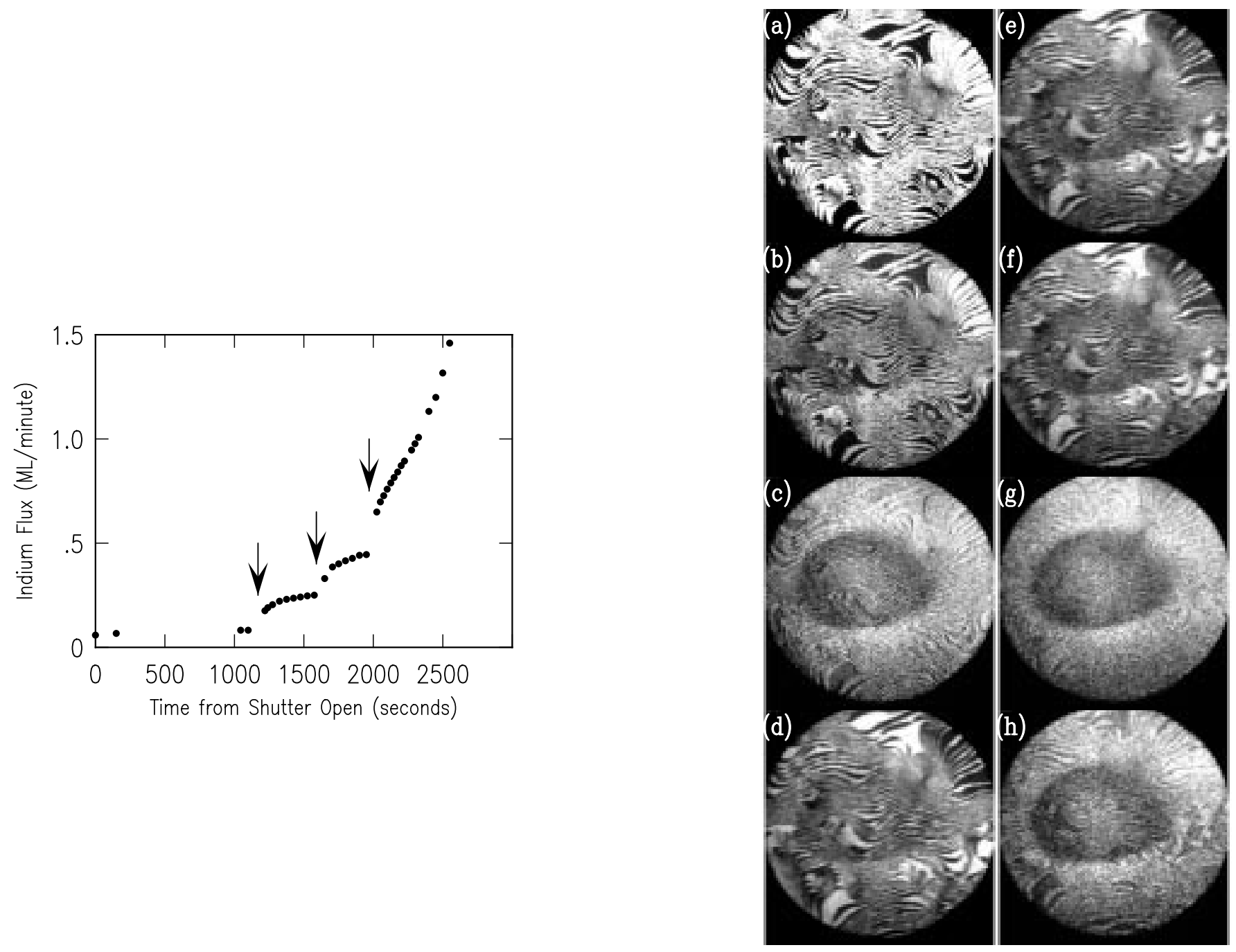
Figure 3.

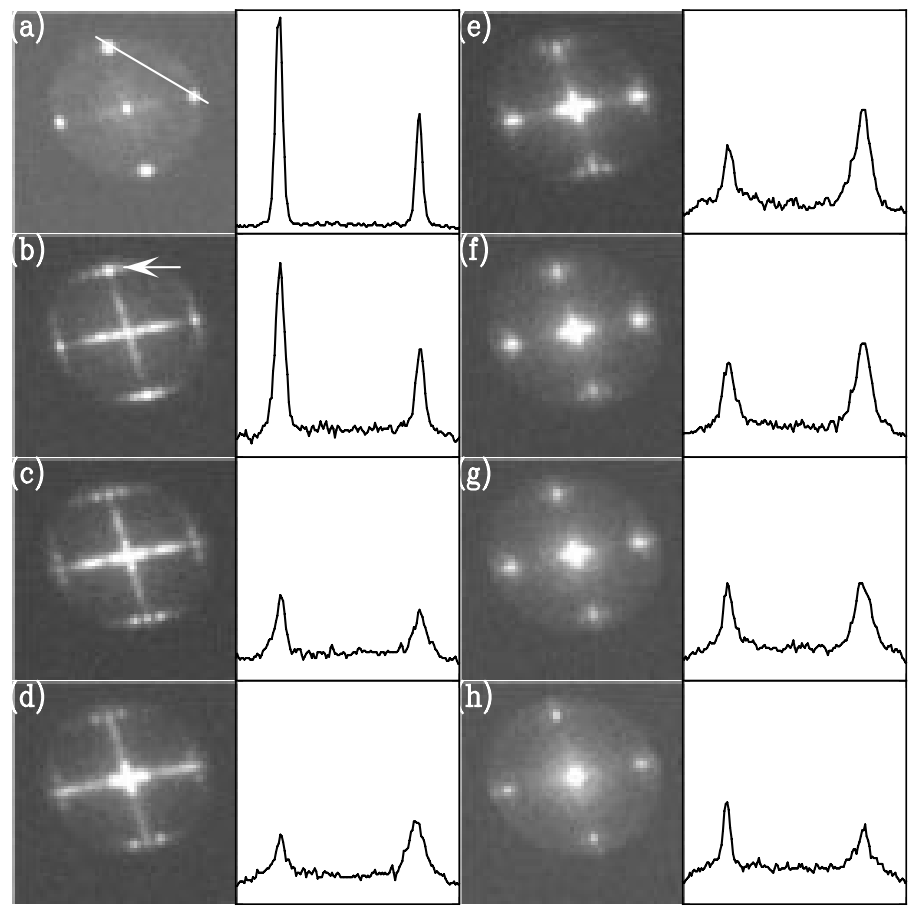

Figure 4 .

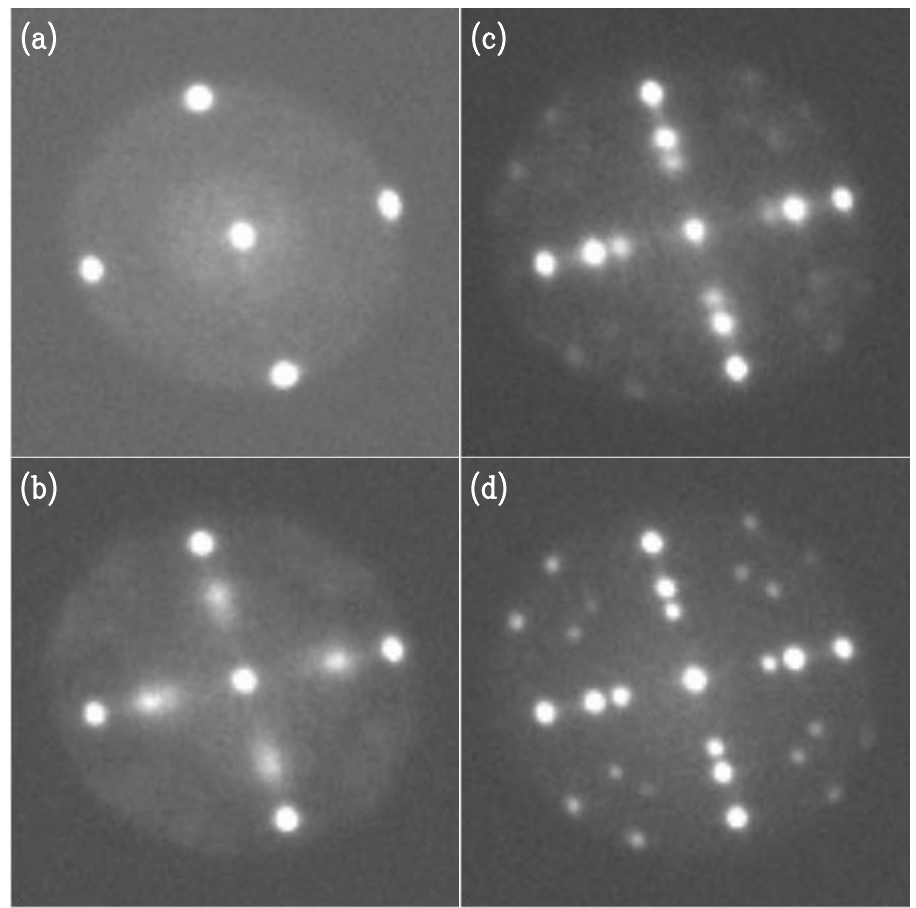


Figure 5.

Figure 6.
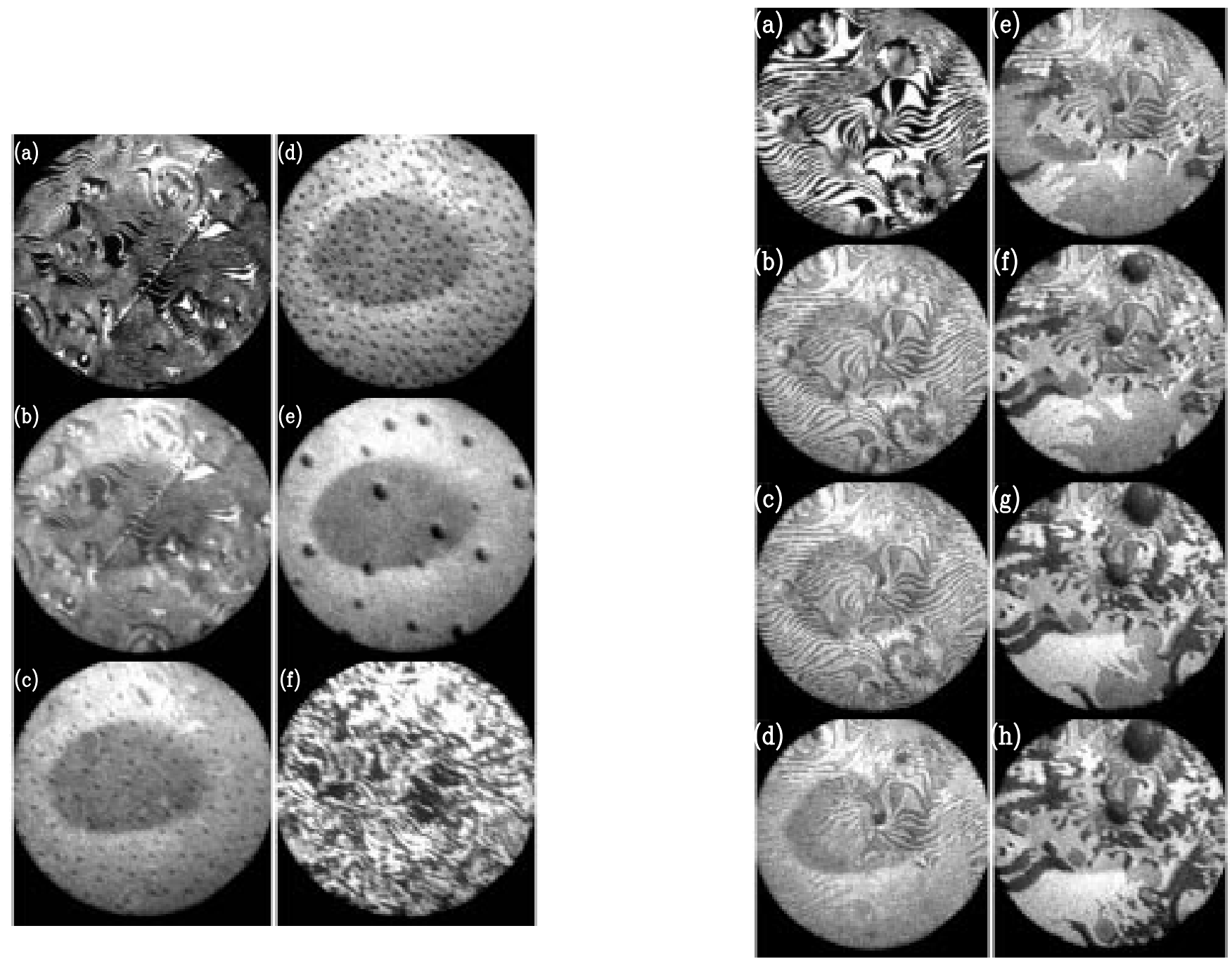
(a)

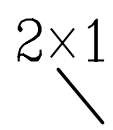

(b)

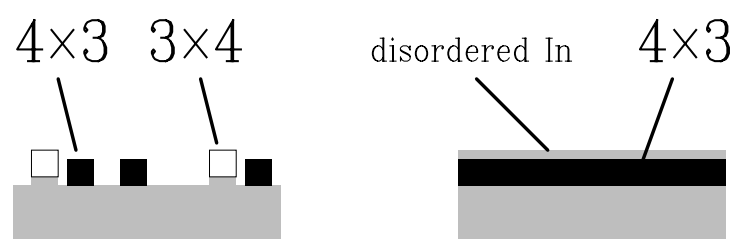

(c)

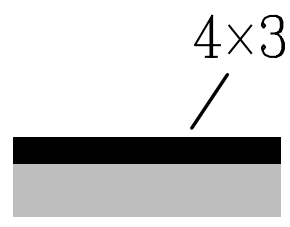

(d)
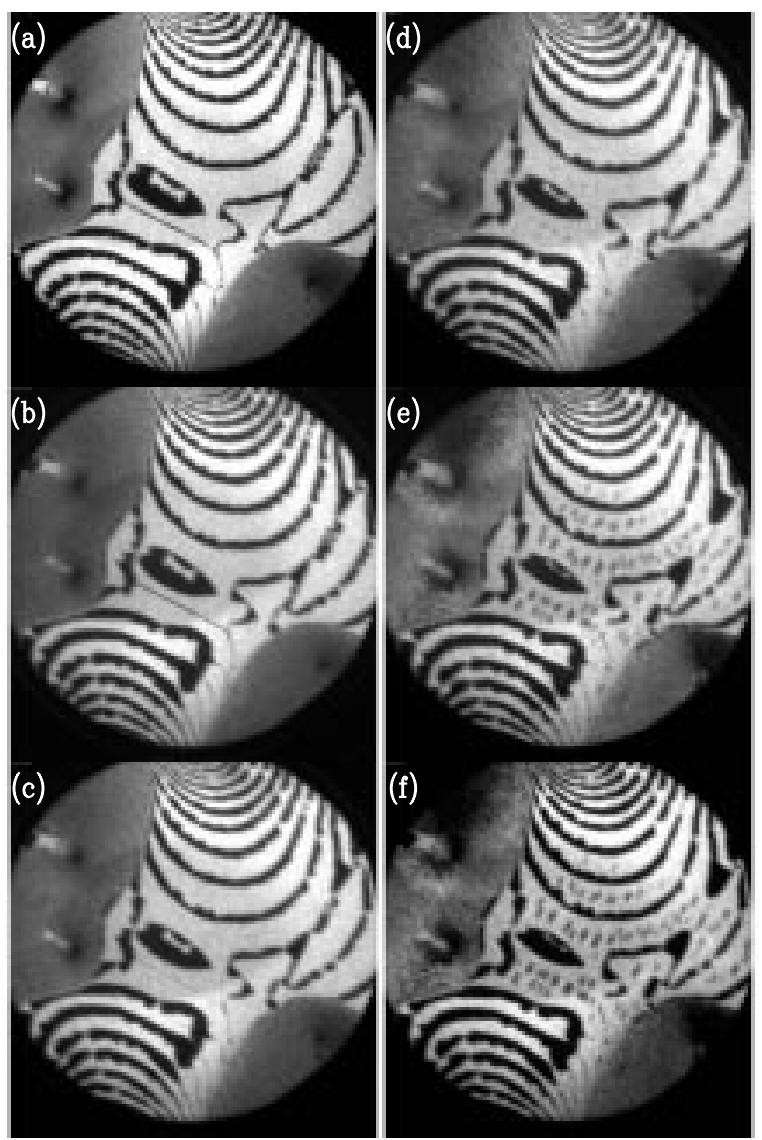

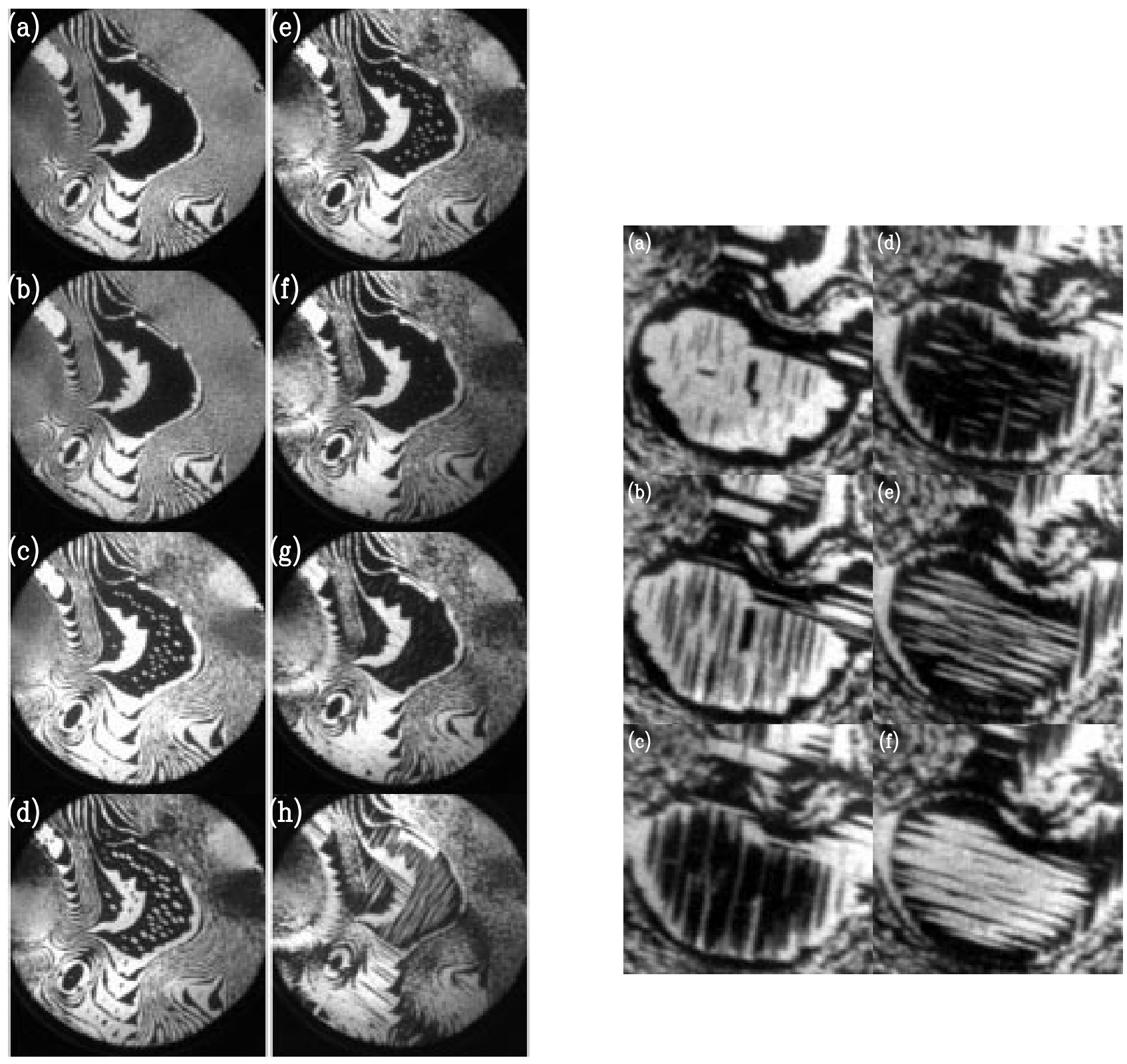
Figure 11.
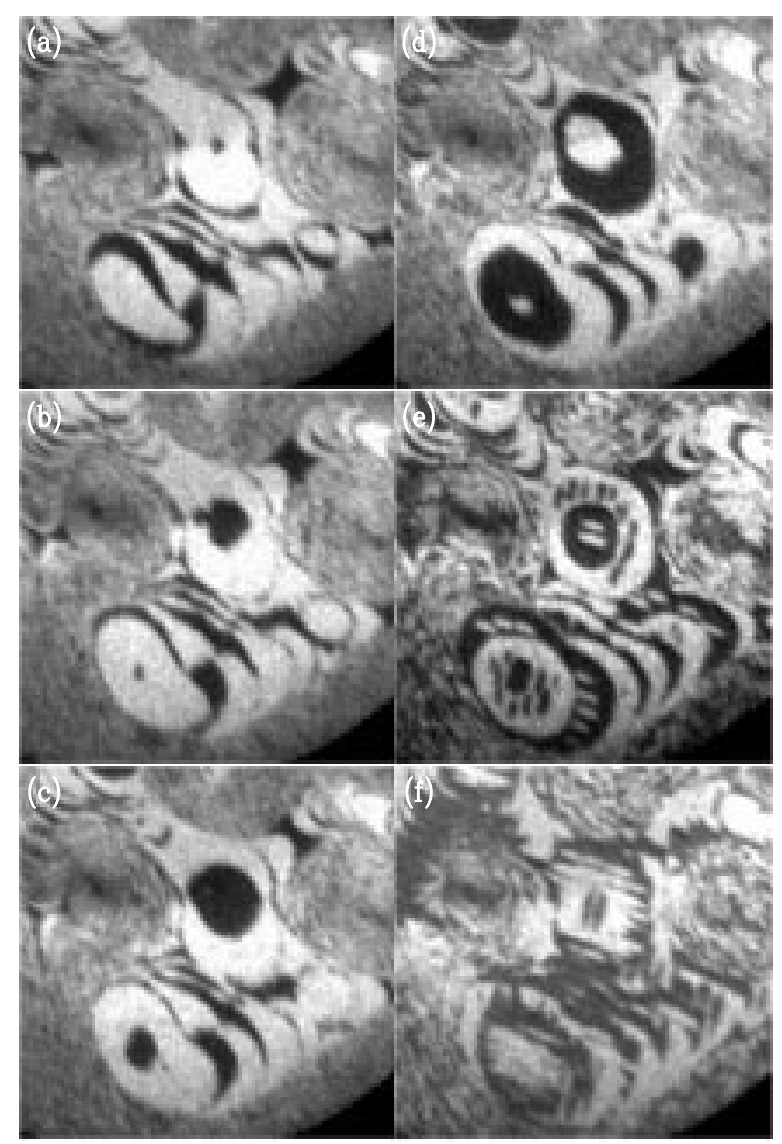